\title{
A method for determining rational fluid production scale in conglomerate reservoir in the stage of high water cut
}

\author{
Wentao Liu ${ }^{1}$, Xiaodong Wang ${ }^{2}$, Chaoliang Zhang, Rui Xue, Guifang Zhu ${ }^{1}$, Jifeng Zhang ${ }^{2}$, Xiaomin Wei ${ }^{2}$, \\ Yanan $\mathrm{Zhao}^{2}$ \\ ${ }^{1}$ Exploration and Development Research Institute of Xinjiang Oilfield, Karamay 834000, China \\ ${ }^{2}$ Research Institute of Exploration and Development, Daqing Oilfield, Daqing 163712, China
}

\begin{abstract}
In view of the problem that water cut rises quickly in conglomerate reservoirs with high water cut, based on the variation law of reservoir water injection and liquid production characteristics, a method for determining the maximum liquid production scale in conglomerate reservoirs with high water cut is established by using reservoir engineering and field statistics.Considering the maximum liquid production capacity at the well end, the maximum injection capacity at the well end and the injecting-production ratio limit to keep the formation energy, a method to determine the maximum liquid production scale in conglomerate reservoir is established to keep the formation energy sufficient.This method ensures that the injection and production ends of the reservoir are coordinated and matched, and the formation energy is sufficient, so that the reservoir development keeps a benign cycle. The research method and conclusion have important reference value and significance for theoretical research and practical application of ultra-high water cut oilfield development.
\end{abstract}

Key words: high water cut;Injection-production coordination; Liquid withdrawal scale

\section{The introduction}

The scale of fluid production is a comprehensive index to reflect the level of oilfield development, production management and economic benefit, as well as a key index for planning, scheme design and dynamic analysis. When the oil field enters the high water cut period, the enhanced production with the continuous increase of injection and production scale as the core has become an important measure to improve the oilfield development effect and enhance the recovery efficiency.However, in addition to directly affected by the process equipment and development benefits, the scale of oilfield fluid production is also related to reservoir physical properties, crude oil physical properties and well pattern pattern.At present, there is no quantitative expression of the relationship between reasonable fluid production scale and related parameters such as reservoir characteristics, well pattern and development stage. On the one hand, excessive liquid production scale will lead to a large amount of waste of materials, as well as the rapid rise of water cut and the continuous decline of oil production, while insufficient liquid production scale will lead to the failure to complete the oil production plan and the guarantee of supply demand.At present, the research on the maximum liquid production scale is mainly determined by maximizing the liquid production capacity of the reservoir, that is, the maximum injection pressure at the injection end and the minimum flow pressure at the production end ${ }^{[1 \sim 3]}$. However, this method has some shortcomings. It does not take into account the coordination between injection and production, that is, whether injection can meet the demand of production. Therefore, it is necessary to establish a method to determine the liquid production limit in the ultra-high water cut stage to meet the oilfield production demand.

\section{Determination method of reasonable liquid production scale in conglomerate reservoir in high water-cut stage}

\subsection{Reasonable injection and production pressure system}

(1) Maximum water injection pressure

The level of water injection pressure is not only related to the injection-production capacity of a well pattern, but also related to the pressure level of the entire injectionproduction pressure system. Too high injection pressure is easy to cause casing damage of oil and water Wells, which brings great adverse effects to oilfield development.However, the injection pressure is too low to meet the demand of injection water, which will lead to the formation energy reduction. The maximum water 
injection pressure can be determined according to the fracturing pressure of the reservoir. Generally, the maximum water injection is about $0.5 \mathrm{MPa}$ lower than the fracturing pressure of the reservoir. In this way, casing damage will not be caused, and reasonable injectionproduction ratio can be guaranteed to meet the needs of the injection water.

$$
\mathrm{P}_{\text {imax }}=\gamma_{\mathrm{o}} \times \mathrm{D}_{\mathrm{o}}-0.5 \text { Type } 1-1
$$

$\mathrm{P}_{\text {imax }}$ Is the maximum water injection pressure of the reservoir, $\mathrm{MPa} ; \gamma_{\mathrm{o}}$ Is the fracture pressure gradient of formation, $\mathrm{MPa} / \mathrm{m} ; \mathrm{D}_{\mathrm{o}}$ is the medium depth of oil layer, $\mathrm{m}$.

(2) Reasonable formation pressure

Formation pressure is a very important factor affecting the effect of oilfield development, which determines the initiative of oilfield development to a large extent.If the formation pressure is too low, the production cannot meet the production allocation requirements, and the porosity and permeability are easily reduced, which is not conducive to the stability of the reservoir structure. The results of development practice statistics and theoretical research show that the reasonable formation pressure is near the original formation pressure. The development practice statistics and theoretical research results show that the reasonable formation pressure is near the original formation pressure, generally should not be higher or lower than the original formation pressure $\mathrm{MPa} . \pm 0.5$

$$
\mathrm{P}_{\mathrm{RR}}=\mathrm{P}_{\mathrm{Ro}} \pm 0.5 \text { Type } 1 \text { and } 2
$$

$\mathrm{P}_{\mathrm{RR}}$ Is the reasonable formation pressure of reservoir, $\mathrm{MPa} ; \mathrm{P}_{\mathrm{RO}}$ Is the original formation pressure of the reservoir, MPa.

(3) Reasonable oil well flow pressure

The flow pressure of oil well generally decreases with the development of oil field, especially in the high and ultrahigh water cut stage, which needs to meet the demand of increasing the drainage amount of oil field.Reservoir water injection pressure, formation pressure and oil well flow pressure are closely related under specific well pattern, oil-well ratio, water-cut stage and reservoir conditions. If two of them are determined, the other one will be determined accordingly. The reasonable flow pressure can be determined according to the injectionproduction pressure equilibrium intersection method.

$$
\mathrm{P}_{\mathrm{R}}=P_{\text {Iwf }}-q_{i} / J_{w}=P_{w f}+q_{L} / J_{L}+\mathrm{c} \text { Type } 1-3
$$

$\mathrm{P}_{\mathrm{R}}$ Is the current formation pressure of the reservoir, $\mathrm{MPa}$; The coefficient $\mathrm{C}$ is determined by the field fitting and is generally between 0 and 1 .

When water injection pressure PiwfTake the maximum Pimax, the oil well flow pressure $\mathrm{P}$ can be obtainedwfThe minimum value of Pwfmin.

\subsection{Maximum injection and production scale}

(1) Reservoir water absorption and fluid production index can be calculated according to field dynamic data In the process of oilfield water injection development, the change of water absorption index and liquid production index is essentially a reflection of the change of seepage resistance near the bottom of oil and water well. With the increasing of water saturation, the seepage resistance keeps decreasing, and the liquid production index increases, while the increase of water absorption index is small.Theory research and development practice shows that high, determining phase conglomerate reservoir, the water injectivity index increase slowly, water injectivity index growth is far lower than the fluid productivity index growth, high water cut stage after production Wells have certain solution space, and the injection well injection has reached saturation, the reservoir of oil phase has been replaced by a water phase.Therefore, the water injection system needs to be strengthened after the high water cut stage.

$$
J_{\mathrm{L}}=\mathrm{q}_{\mathrm{L}} /\left(\mathrm{P}_{\mathrm{R}}-\mathrm{P}_{\mathrm{wf}}\right) \text { Type 1-4 }
$$

$\mathrm{J}_{\mathrm{L}}$ Is liquid production index, $\mathrm{m}^{3} /\left(\mathrm{d}\right.$. MPa); $\mathrm{q}_{\mathrm{L}}$ Is the daily production fluid of a single well, $\mathrm{m}^{3} / \mathrm{d}$;

$$
J_{\mathrm{i}}^{*}=\mathrm{q}_{\mathrm{i}} / \mathrm{P}_{\mathrm{i}}^{*} \text { Type 1-5 }
$$

$\mathrm{J}_{\mathrm{i}}^{*}$ Is the apparent water absorption index, $\mathrm{m}^{3} /$ (d. $\mathrm{MPa}$ ); $\mathrm{q}_{\mathrm{i}}$ Is single well daily water injection, $\mathrm{m}^{3} / \mathrm{d} ; \mathrm{P}_{\mathrm{i}}^{*}$ Is the wellhead water injection pressure, $\mathrm{MPa}$.

(2) The maximum scale of water injection and liquid production can be calculated according to the injectionproduction pressure limit

$$
\mathrm{Q}_{\mathrm{L} \text {-o max }}=n_{o} \times J_{L} \times\left(\mathrm{P}_{\mathrm{RR}}-\mathrm{P}_{\text {wfmin }}\right) \text { Type 1-6 }
$$

$\mathrm{Q}_{\mathrm{L}-\mathrm{max}}$ Is the maximum daily liquid production scale at the end of the well, $\mathrm{m}^{3} ; \mathrm{n}_{\mathrm{o}}$ Is the number of oil Wells, mouth;

$$
Q_{i \max }=n_{w} \times J_{\mathrm{I}}^{*} \times P_{i \max }^{*} \text { Type 1-7 }
$$

Qimax Is the maximum daily water injection scale at the well end, $\mathrm{m}^{3} ; \mathrm{n}_{\mathrm{w}}$ Is the number of Wells, mouth.

\subsection{The injection-production ratio limit for the oil field to maintain or restore the formation energy}

Injection-production ratio is a comprehensive index to measure the replenisation of underground energy and the degree of cavitation. It is a comprehensive index to represent the balance of injection-production in the process of oilfield water injection development, and to reflect the relationship between liquid production, water injection and formation pressure. It is an important basis for the planning and design of oilfield water injection.Reasonable injection-production ratio is an important guarantee to maintain reasonable formation pressure, so as to make the oilfield have strong liquid and oil production capacity, reduce invalid energy consumption, and obtain high oil recovery efficiency.Field dynamic statistics is mainly used to determine the injection-production ratio to maintain or restore formation energy for a long period of oilfield development.Considering the field practice, the injectionproduction ratio should be kept above 1.0 due to the 
influence of formation void, injection water overflow and liquid discharge measures.According to the recent production performance data, the variation characteristics of injection-production ratio and formation pressure/total pressure difference are analyzed according to the actual curve of injection-production ratio and formation pressure/total pressure difference. The reasonable injection-production ratio under the condition of maintaining formation energy is determined according to the change trend or inflection point of the two.According to the curve of injection-production ratio and formation pressure variation of typical conglomerate reservoirs in western China, the reasonable injection-production ratio of this reservoir is about 1.1 .

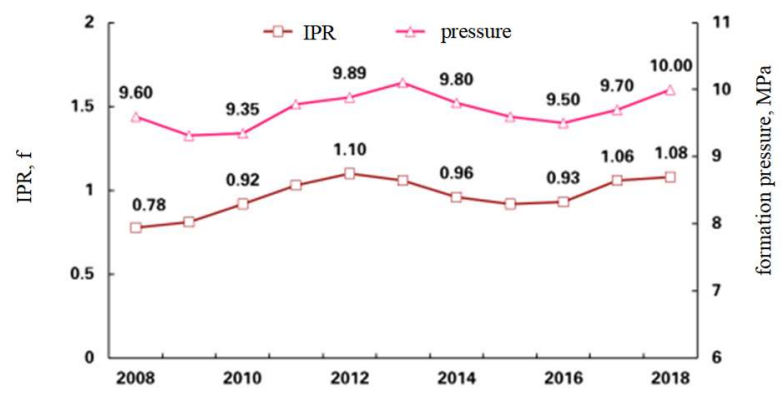

Fig. 1 Variation curve of inject-production ratio and formation pressure in $\mathrm{B} 2 \mathrm{D}$ conglomerate reservoir

\subsection{Determine the maximum fluid production scale based on the coordination between injection and production ends}

The ratio between the maximum water injection scale and injection-production ratio at the well end of the reservoir is defined as the maximum liquid production scale at the well end. If the liquid production scale exceeds the maximum water production scale, the formation energy of the reservoir will be reduced and the oil layer will be degassing, which is not favorable for improving the development effect and enhancing the oil recovery.The maximum fluid production scale based on the well end and the minimum value based on the well end are taken as the maximum fluid production scale of the reservoir.

$$
\mathrm{Q}_{\mathrm{L} \text {-wmax }}=\mathrm{Q}_{\text {imax }} / \mathrm{IPR} \text { Type 1-8 }
$$

$\mathrm{Q}_{\mathrm{L}-w \max } \mathrm{Is}$ the maximum daily liquid production scale of the reservoir based on the well end, $\mathrm{m}^{3}$; IPR is the injection-production ratio, dimensionless;

$$
\mathrm{Q}_{\mathrm{LR}}=\min \left(\mathrm{Q}_{L_{- \text {o max }}}, \mathrm{Q}_{L \text {-w max }}\right) \text { Type 1-9 }
$$

$\mathrm{Q}_{\mathrm{LR}}$ Is the maximum daily liquid production scale of the reservoir, $\mathrm{m}^{3}$.

\section{Instance application}

\subsection{Geological and development characteristics of B2D conglomerate reservoir}

(1) Geological features

B2D conglomerate reservoir is located in a basin in western China, with flat surface and convenient transportation.The reservoir develops five sand formations from bottom to top.Subdivided into 11 small layers and 17 single sand layers. The main reservoir is gravelly braided river deposit, mainly developed braided channel and core beach microfacies. The average porosity and permeability of the reservoir are 18.5 and $130.5 \mathrm{mD}$, respectively. It is a medium porosity and medium permeability reservoir.

(2) Mining characteristics

The B2D conglomerate reservoir was put into development in 1959. By December 2018, the recovery degree of the reservoir was $40.63 \%$, the comprehensive water cut was $78.1 \%$, and the recovery rate was $6.75 \%$.According to the change of liquid production rate in $\mathrm{B} 2 \mathrm{D}$ oilfield, in the low water cut stage (water cut less than $20 \%$ ), the oilfield is in the upper production stage, and the liquid production rate rises rapidly.In the middle water cut stage (water cut is between $20 \%$ and $60 \%$ ), the liquid production rate is relatively stable.Into high water cut stage (water cut is more than $60 \%$ ), oil field in the stage of high and stable yield, liquid withdrawal rate rising fast, but since 2013, as the growth of the scale of liquid withdrawal, a rapidly rising gas-oil ratio, single well to reduce oil and water well casing damage, seriously affecting the effects of oilfield exploitation of improvement and orderly operation of production.

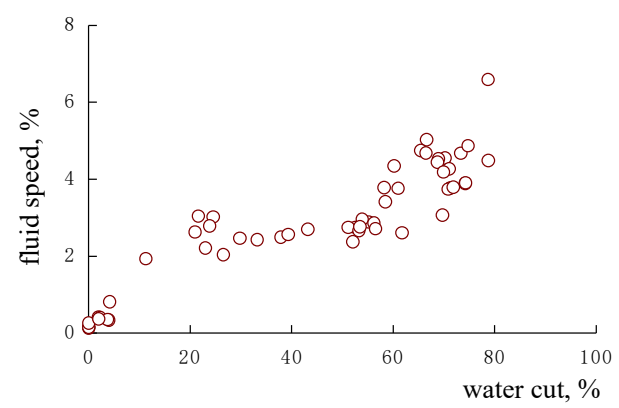

Fig. 2 Variation curve of fluid production velocity in B2D reservoir

\subsection{Determination results of reasonable liquid production scale}

Taking B2D conglomerate reservoir as an example, statistical calculation is carried out according to the above calculation method.According to the field statistics and reservoir engineering methods, the reasonable injectionproduction ratio is increased to 1.05 , the water injection pressure is increased by $1.6 \mathrm{MPa}$, the reasonable formation pressure is restored to $0.9 \mathrm{MPa}$ and remains near the original formation pressure, and the average daily liquid production scale is increased by $80 \mathrm{~m}^{3}$ After the 
adjustment, the liquid volume was stable, the formation pressure recovered to $10.0 \mathrm{MPa}$, and the liquid production scale was $358 \mathrm{~m}^{3} / \mathrm{d}$ rises to $437 \mathrm{~m}^{3} / \mathrm{d}$, it is estimated that the recovery rate will be increased by about $1.2 \%$, which can produce great economic benefits and effectively guide the adjustment of reservoir development.

Table 1. Calculation table of maximum liquid production scale of $\mathrm{J} 1 \mathrm{~b}$ reservoir in conglomerate reservoir in east Qidong 1

\begin{tabular}{|c|c|c|c|c|}
\hline parameter & unit & $\begin{array}{c}\text { The } \\
\text { curre } \\
\text { nt } \\
\text { value }\end{array}$ & $\begin{array}{c}\text { Maximum/reason } \\
\text { able }\end{array}$ & $\begin{array}{c}\text { Target } \\
\text { adjustme } \\
\text { nt } \\
\text { differenc } \\
\mathrm{e}\end{array}$ \\
\hline $\begin{array}{c}\text { Well } \\
\text { control } \\
\text { reserves }\end{array}$ & $\begin{array}{c}10^{4} \mathrm{~T} / \mathrm{mou} \\
\text { th }\end{array}$ & 4.01 & / & I \\
\hline $\begin{array}{c}\text { The } \\
\text { average } \\
\text { water cut }\end{array}$ & $\%$ & 78.11 & l & / \\
\hline $\begin{array}{l}\text { The well } \\
\text { number }\end{array}$ & mouth & 33 & I & / \\
\hline $\begin{array}{l}\text { Number } \\
\text { of Wells }\end{array}$ & mouth & 20 & I & / \\
\hline $\begin{array}{c}\text { Fluid } \\
\text { productivi } \\
\text { ty index, }\end{array}$ & $\begin{array}{l}\mathrm{m}^{3} /(\mathrm{d} . \\
\mathrm{MPa})\end{array}$ & 2.1 & / & / \\
\hline $\begin{array}{c}\text { Water } \\
\text { injectivity } \\
\text { index }\end{array}$ & $\begin{array}{l}\mathrm{m}^{3} /(\mathrm{d} . \\
\mathrm{MPa})\end{array}$ & 2.5 & / & / \\
\hline $\begin{array}{l}\text { Wellhead } \\
\text { water } \\
\text { injection } \\
\text { pressure }\end{array}$ & $\mathrm{MPa}$ & 8.2 & 9.8 & +1.6 \\
\hline $\begin{array}{c}\text { Reservoir } \\
\text { formation } \\
\text { pressure }\end{array}$ & Mpa & 9.7 & 10.6 & +0.9 \\
\hline $\begin{array}{c}\text { Bottom } \\
\text { hole } \\
\text { pressure } \\
\text { of oil well }\end{array}$ & Mpa & 4.1 & 4.3 & +0.2 \\
\hline $\begin{array}{c}\text { The water } \\
\text { flooding } \\
\text { scale }\end{array}$ & $\mathrm{m}^{3} / \mathrm{d}$ & 410 & 490 & +80 \\
\hline $\begin{array}{c}\text { Injection- } \\
\text { productio } \\
\text { n ratio }\end{array}$ & $\mathrm{f}$ & 0.88 & 1.05 & +0.17 \\
\hline $\begin{array}{c}\text { Liquid } \\
\text { withdraw } \\
\text { al scale }\end{array}$ & $\mathrm{m}^{3} / \mathrm{d}$ & 358 & 437 & +79 \\
\hline
\end{tabular}

\section{Conclusion}

Based on reservoir engineering and field statistics, a method for determining the maximum fluid production size of conglomerate reservoir in high water-cut stage is established.Considering the maximum liquid production capacity at the well end, the maximum injection capacity at the well end and the injecting-production ratio limit to keep the formation energy sufficient, a method to determine the maximum liquid production scale of the reservoir is established.This method ensures that the injection and production ends of the reservoir are coordinated and matched, and the formation energy is sufficient, so that the reservoir development keeps a benign cycle.This method avoids the previous shortcomings, such as formation energy reduction, casing damage of oil and water well and degassing of formation crude oil, which only consider the production capacity of well end but fail to fully consider the injection capacity of injection end.

\section{References}

1. Ji Bingyu, LI Yanxing. Main technical countermeasures for enhancing oil recovery in high water cut stage of la, sa and xing oilfields [J]. Petroleum geology \& oilfield development in daqing,2004,23(5):47-53.

2. Zhang Xin-zheng, ZHANG Lie-hui, Xiong Yu. Petroleum geology \& oilfield development in daqing,2005,24(3):48-50.

3. Wang Zhijun, Liu Xiuhang, Dong Jing.Quantitative evaluation method and adjustment countermeasures for injection-production adaptability of oilfield block in late period of high water cut [J]. Petroleum geology and oilfield development in daqing, 2005,24 (6) : 5153. 